\title{
Simultaneous preaxillary mound correction using liposuction through a breast augmentation incision
}

\author{
Ju Young Go, \\ Daniel Seungyoul Han \\ DH Plastic Surgery, Busan, Korea
}

This article was presented as a poster at PRS Korea 2017 on November 10-12, 2017 in Seoul, Korea.

\begin{abstract}
The preaxillary mound (PAM) is an aesthetic unit that is often overlooked in breast surgery, although it is intimately associated with the outcomes of breast augmentation. Over 18 months, a series of 76 patients who underwent simultaneous PAM correction using liposuction through a breast augmentation incision were reviewed retrospectively to evaluate the effectiveness of this approach. The mean follow-up was 9 months. In total, 150 PAMs were treated with suction alone. The inframammary approach was used in 72 cases, and the periareolar approach was used in four cases. Satisfactory results were achieved in $99 \%$ of cases. One patient presented postoperatively with remaining tissue. The use of a breast augmentation incision to treat PAM is an effective and safe technique that eliminates the need for an additional suction cannula incision.
\end{abstract}

Keywords Accessory breast / Lipectomy / Mammoplasty / Suction

\section{INTRODUCTION}

The preaxillary mound (PAM) is a fibrofatty tissue anterior to the axilla on the chest wall that often looks like fat sticking out of the lateral side of one's bra. This aesthetic unit is often overlooked in breast surgery, but its presence impacts breast aesthetics. Furthermore, breast surgery, especially breast augmentation, could exacerbate its appearance by pushing it superiorly [1]. Therefore, when we perform breast augmentation, assessing the PAM and simultaneously resolving any issues involving it are very important in order to obtain satisfactory aesthetic outcomes.

Tissue can be removed from the PAM by liposuction alone or by direct excision [2-6]. While direct excision facilitates adequate tissue resection, it results in long scars and occasionally creates a dead space. Many reports have stated that liposuction alone can yield good results [2,3], but this method can also have scar-related prob-

Received: Oct 22, 2018 Revised: Dec 3, 2018 Accepted: Dec 6, 2018 Correspondence: Ju Young Go DH Plastic Surgery, 21 Gaya-daero 784beon-gil, Busanjin-gu, Busan 47285, Korea

Tel: +82-51-1644-7520, Fax: +82-51-711-7527, E-mail: j.juliet.go@gmail.com

Copyright $\odot 2019$ The Korean Society for Aesthetic Plastic Surgery.

This is an Open Access article distributed under the terms of the Creative Commons Attribution Non-Commercial License (http://creativecommons.org/licenses/by-nc/4.0/) which permits unrestricted non-commercial use, distribution, and reproduction in any medium, provided the original work is properly cited. www.e-aaps.org lems, although such scars are relatively small.

In our practice, simultaneous PAM correction using liposuction is performed through a breast augmentation incision, providing additional benefits, along with satisfactory results and minimal complications.

\section{IDEA}

The boundaries of the PAM, in addition to the usual breast augmentation design, were marked in the standing position. The patient lay down in a supine position with the arms abducted. Surgery was performed, through the inframammary approach or the periareolar approach, with the patient under general anesthesia. A dual-plane pocket was preferred, and the pockets were electrosurgically dissected. After completing all dissections for the implant pockets, the PAM was infiltrated with tumescent fluid using the superwet technique. Each liter of tumescent solution consisted of $1 \mathrm{~L}$ of Ringer's lactate solution, $10 \mathrm{~mL}$ of $1 \%$ lidocaine, and $1 \mathrm{~mL}$ of 1:1,000 epinephrine. The total amount of this solution was usually no more than $150 \mathrm{~mL}$ on each side.

A 3-mm cannula was used to remove the tissue from the PAM area under gentle pressure from the surgeon's palm. All cannulas, including those used for tumescent infiltration and suction, were inserted into the augmentation approach site, and then were introduced between the muscle and glandular layer after checking the 

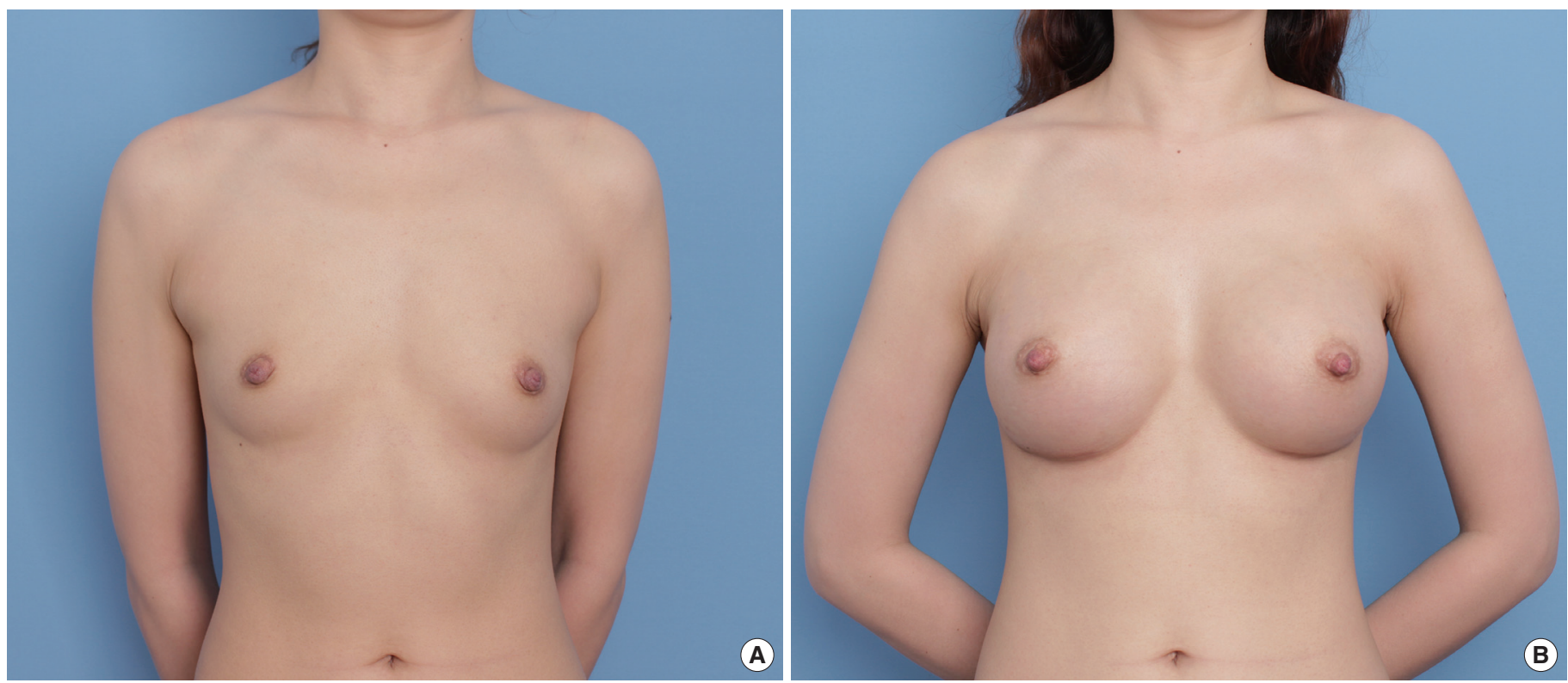

Fig. 1. A 36-year-old woman, before (A) and 3 months after (B) inframammary breast augmentation and preaxillary mound suction (Motiva Implants Ergonomix; right $340 \mathrm{~mL}$ and left $320 \mathrm{~mL}$ ).
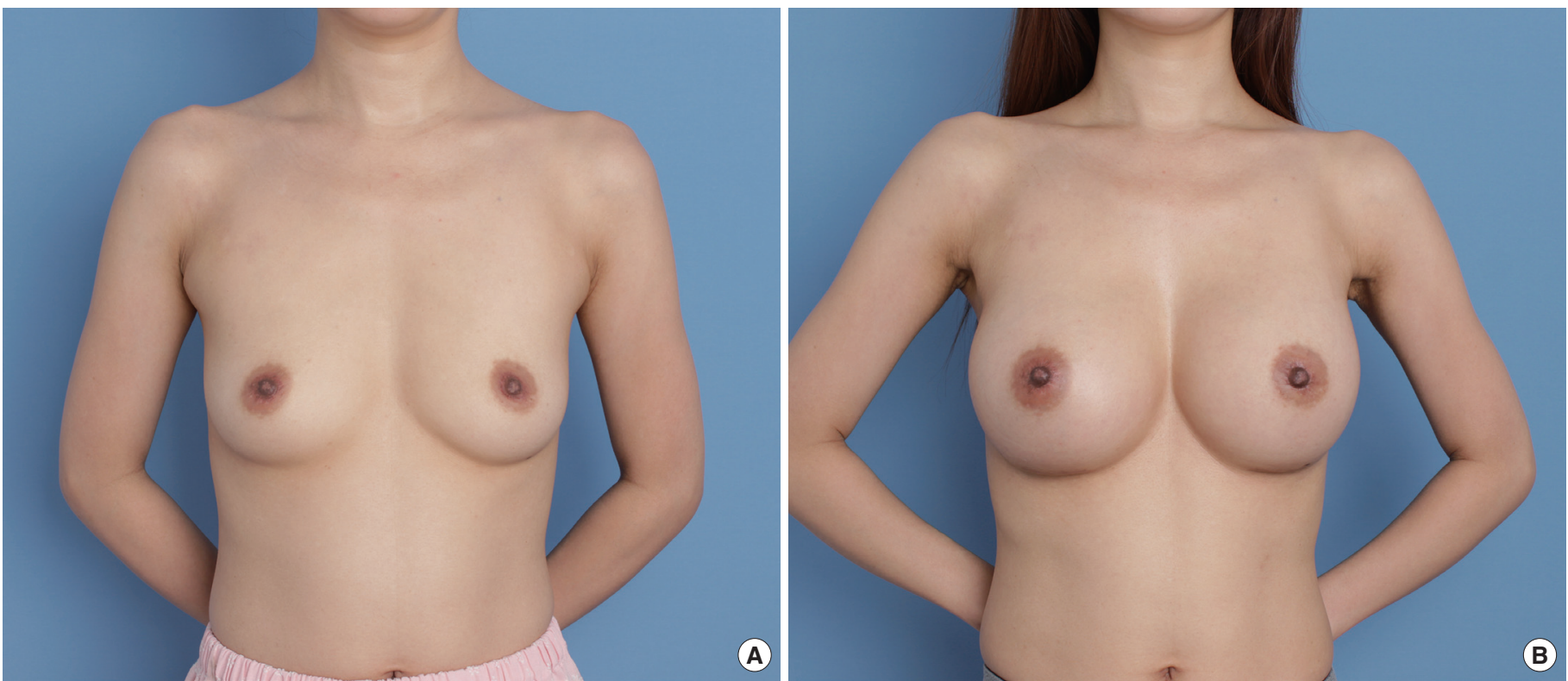

Fig. 2. A 35-year-old woman, before (A) and 6 months after (B) inframammary breast augmentation and preaxillary mound suction (Sebbin, LS 70 ; right $330 \mathrm{~mL}$ and left $330 \mathrm{~mL}$ ).

end of the pectoralis major muscle. All patients underwent suctionassisted lipoplasty. After completing the liposuction procedure, saline irrigation and triple antibiotic solution were administered into the pocket. The implant was inserted using a Keller Funnel (Keller Medical Inc., Stuart, FL, USA), and the wound was closed using the conventional method. There was usually minimal bleeding, and drains were not usually inserted. Postoperatively, the patient was fitted with axillary pads bilaterally by a strapped support bra or compression band. This was done because extensive aspiration would result in bruising or further sagging of the axillary fold.

This liposuction method using a breast augmentation incision for resolving PAM was used in 76 patients from December 2016 to June 2018. The follow-up period ranged from 2 months to 18 months (average, 9 months). The inframammary approach was used in 72 cases, and the periareolar approach was used in four cases. Seventy-four of the procedures were bilateral, and two were 

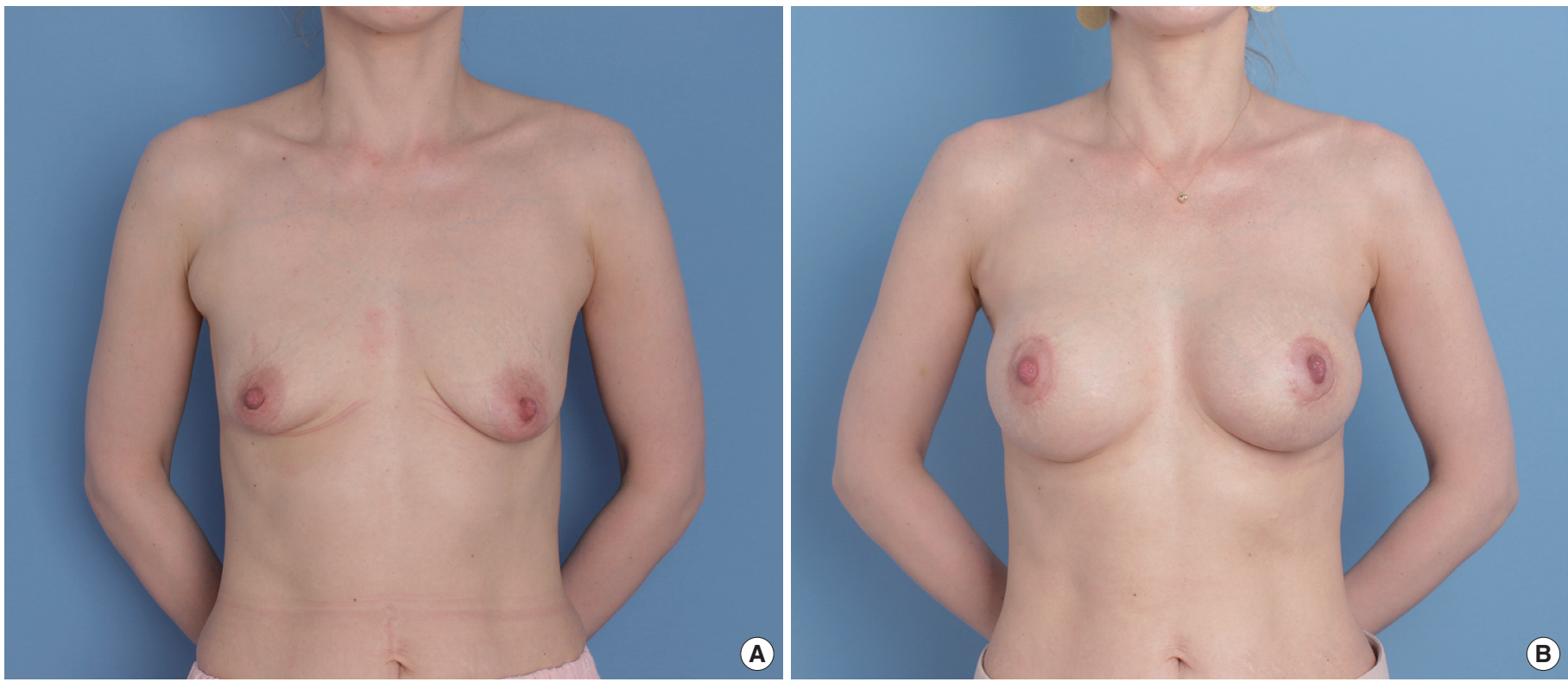

Fig. 3. A 38-year-old woman, before (A) and 5 months after (B) periareolar breast augmentation with mastopexy and preaxillary mound suction (Motiva Implants Ergonomix; right $300 \mathrm{~mL}$ and left $320 \mathrm{~mL}$ ).
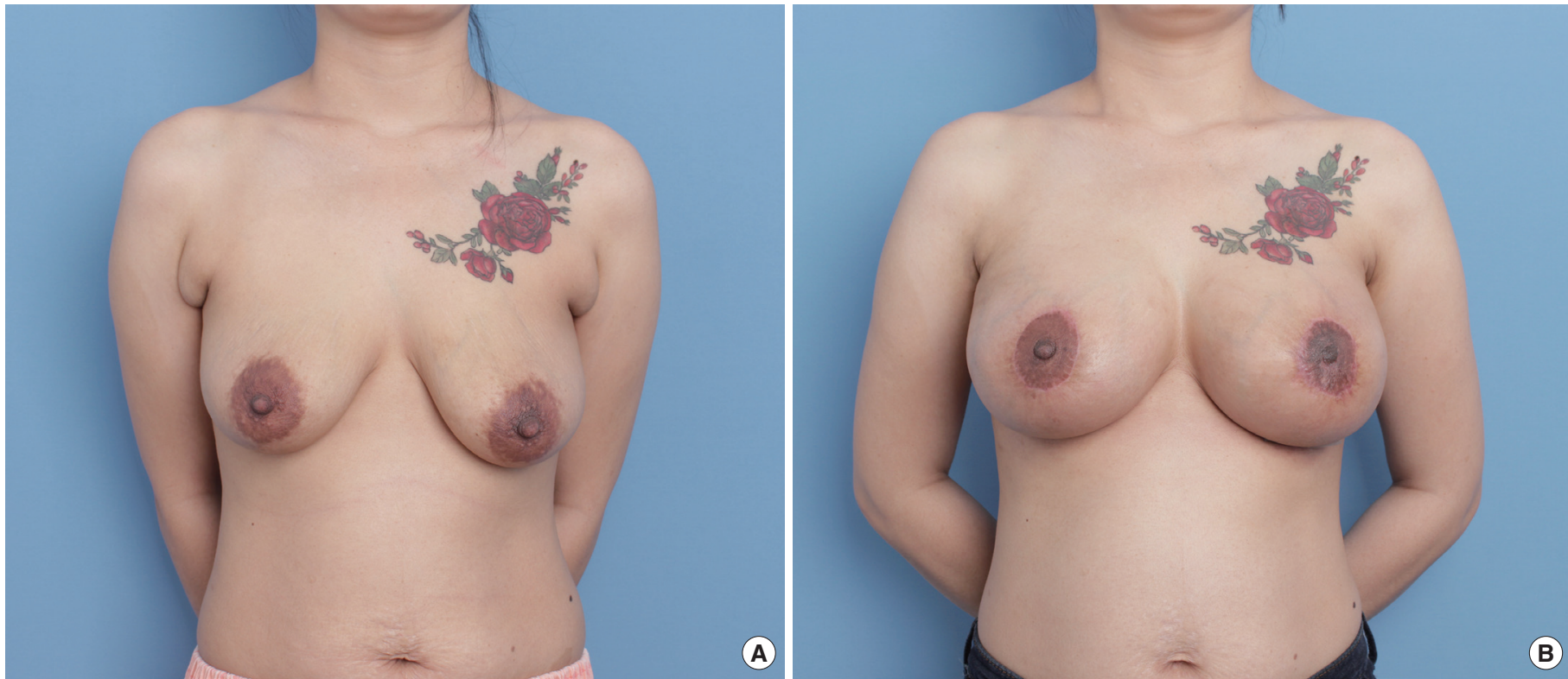

Fig. 4. A 30-year-old woman, before (A) and 2 months after (B) periareolar breast augmentation with mastopexy and preaxillary mound suction (Sebbin, LS 70; right $330 \mathrm{~mL}$ and left $300 \mathrm{~mL}$ ).

unilateral. The average age of the patients was 35 years, and their average body mass index (BMI) was $19.9 \mathrm{~kg} / \mathrm{m}^{2}$. The average amount of suction for 1 PAM was $38 \mathrm{~mL}$ (range, 15-60 mL). Satisfactory results were achieved in $99 \%$ of cases, although one patient presented postoperatively with remaining tissue. The outcomes of the technique are illustrated in Figs. 1-4.

\section{DISCUSSION}

Martinovic and Blanchet [1] proposed the PAM as a sixth subunit of the breast. The PAM comprises fibrofatty tissue anterior to the axilla on the chest wall and distinct from the tail of Spence, which is always contiguous with the breast. Most patients with a PAM want it to be removed for aesthetic, rather than clinical, reasons. The bulging flesh of the armpit is not only embarrassing when 
wearing sleeveless clothes or underwear, but also makes the arms look shorter and the breast look wider [5].

A PAM is generally considered to be an area of armpit fat, but it is also considered to be a mild type of accessory breast [4]. Usually, the diagnosis of accessory axillary breast tissue is based on its initial appearance during pregnancy or by a history of cyclic changes during the menstrual period. According to the classification proposed by Bartsich and Ofodile [4], almost all of our patients had type II or III axillary breasts. If there was too much excess skin, the palpable mass was too hard, or an accessory nipple was present, the direct excision method was used, and such patients were excluded from this study. Because these cases possibly involved other diseases, we required more accurate tissue samples than it would have been possible to obtain using liposuction.

Various methods for resolving cases of PAM or an accessory breast have been developed. Treatment modalities include direct excision with various designs [4-6], as well as tumescent liposuction $[2,3]$. While direct excision facilitates adequate tissue resection, it may result in long scars and a relatively irregular contour. It also usually requires percutaneous drain placement to prevent hematoma. In contrast, suction usually suffices for recontouring the axilla, and it is preferable to direct excision. It has the advantages of involving a smaller incision, feathering of tissue removal for a smoother contour, and creating less dead space. However, using simple tumescent liposuction alone makes it difficult to remove dense fibrous tissue from the PAM. If good results cannot be obtained by simple lipoplasty, ultrasound-assisted lipoplasty, powerassisted lipoplasty, or using a microdebrider [2] could be more effective. However, the aspirated tissue needs to be investigated by a cytologist to rule out the potential for malignancy.

Combining procedures, as in this method, has numerous advantages, such as a single recovery period and reduced surgical costs, with only one anesthesia and facility fee. However, in a multivariate analysis, Kaoutzanis et al. [7] confirmed that single cosmetic procedures in combination with liposuction had a statistically significantly higher incidence of major complications than cosmetic procedures performed alone. When examining breast augmentation performed with liposuction, combined procedures had a higher risk of confirmed venous thromboembolism, pulmonary complications, and infection than solitary procedures. The risk factors identified in that article were obesity and length of surgery. However, the PAM is not unique to obese patients, as shown by the fact that the average BMI of the patients in our study was $19.9 \mathrm{~kg} / \mathrm{m}^{2}$, and the amount of suction was not proportional to the BMI of the patient. Furthermore, since performing PAM suction only adds 10 to 20 additional minutes to breast augmentation, it does not raise concerns about patient safety due to prolonged anesthesia time. Moreover, although breast augmentation and PAM suction use the same incision window, the concerns about surgical site infection are also minimal. This is because PAM suction is performed over the pectoralis major muscle, while the pockets for the implants are under this muscle.

Of course, additional incisions may be placed around the armpits to perform liposuction in response to these concerns; however, two of the major complications of liposuction are wound-related and scar-related problems [6,7]. These problems may occur because of easily visible scars due to poor placement of incisions, depressed scars due to over-liposuctioning in the vicinity of the incision, and hyperpigmented scars due to skin bruising following repeated passes by the cannula. Using a relatively long and wide incision, such as an inframammary or periareolar incision, could resolve these possible problems.

Although patients with a mild PAM may not have been concerned about it before breast augmentation, PAMs usually becomes more exaggerated with breast augmentation. Therefore, it is important to think of the PAM as a subunit that needs to be addressed during breast augmentation, rather than as a separate issue. The advantage of our method is that we were able to correct the PAM simultaneously, thus making the results of breast augmentation more aesthetically pleasing by organizing the breast and subsequent armpit lines. This technique also has the advantage of allowing us to correct the PAM without any additional scars around the armpit.

Suction-assisted PAM correction suffices for recontouring the axilla, and it makes the overall breast shape appear better, especially when performed simultaneously with breast augmentation. This method should be strongly considered in patients with a PAM undergoing a primary breast augmentation procedure. This is a simple and reliable method for PAM correction that leaves only one inframammary or periareolar scar. The simultaneous use of a breast augmentation incision in PAM treatment results in an excellent cosmetic result without additional scars.

\section{NOTES}

\section{Conflict of interest}

No potential conflict of interest relevant to this article was reported.

\section{Ethical approval}

The study was performed in accordance with the principles of the Declaration of Helsinki.

\section{Patient consent}

The patients provided written informed consent for the publication and the use of their images.

\section{ORCID}

Ju Young Go https://orcid.org/0000-0002-5808-1806 


\section{REFERENCES}

1. Martinovic ME, Blanchet NP. BFACE: a framework for evaluating breast aesthetics. Plast Reconstr Surg 2017;140:287e-295e.

2. Jeremy SM, Jack CS, Vincent YK, et al. The use of microdebrider for the treatment of accessory axillary breast. J Plast Reconstr Aesthet Surg 2012;65:e301-4.

3. Fan J. Removal of accessory breasts: a novel tumescent liposuction approach. Aesthetic Plast Surg 2009;33:809-13.
4. Bartsich SA, Ofodile FA. Accessory breast tissue in the axilla: classification and treatment. Plast Reconstr Surg 2011;128:35e-36e.

5. Kim YS. Correction of accessory axillary breast tissue without visible scar. Aesthet Surg J 2004;24:531-5.

6. Papadimitriou AM, Yiacoumettis AM. A method for correcting prominent axillary folds. Plast Reconstr Surg 1999;104:595-6.

7. Kaoutzanis C, Gupta V, Winocour J, et al. cosmetic liposuction: preoperative risk factors, major complication rates, and safety of combined procedures. Aesthet Surg J 2017;37:680-94. 